\title{
Assessing Needs for Gerontological Education in Urban and Rural Areas of Ohio
}

\author{
Daniel J. Van Dussen ${ }^{1}$, Suzanne M. Leson ${ }^{2}$, Eric S. Emerick ${ }^{1}$, Joseph A. Voytek ${ }^{1}, \&$ Heidi H. Ewen ${ }^{3}$ \\ ${ }^{1}$ Department of Gerontology, Youngstown State University, Youngstown, Ohio, USA \\ ${ }^{2}$ Department of Human Ecology, Gerontology Steering Committee, Youngstown State University, Youngstown, Ohio, \\ USA \\ ${ }^{3}$ Institute of Gerontology, University of Georgia, Athens, Georgia, USA \\ Correspondence: Daniel J. Van Dussen, Department of Gerontology, Youngstown State University, Youngstown, Ohio, \\ USA
}

Received: September 10, 2015 Accepted: September 16, $2015 \quad$ Online Published: October 8, 2015

doi:10.11114/jets.v4i1.1079

URL: http://dx.doi.org/10.11114/jets.v4i1.1079

\begin{abstract}
Purpose of the Study: This project surveyed health care professionals from both urban and rural care settings in Ohio and examined differences in professionals' needs and interests in continuing gerontological education.

Design and Methods: The survey data were analyzed for 766 health care professionals descriptively, using cross-tabulations and $c^{2}$ tests.

Results: The key findings were that professionals are willing to drive a maximum time of one-hour per week to travel one way to attend classes/workshops to earn gerontology certificate among both urban and rural drivers $[(4, \mathrm{~N}=514)=11.65, p=.020]$. Distance learning was the most preferred method for furthering gerontological education for both urban (39\%) and rural (49\%) participants. One quarter or fewer of the professionals were interested in obtaining a master's degree. Of slightly greater interest was pursuit of a graduate gerontology certificate ( $25 \%$ urban and $28 \%$ rural). It is concluded that there is a need and desire for professionals working with aging populations in Ohio to pursue additional education. Preferences for obtaining education inform us of the ways in which education can best be delivered.

Implications: Youngstown State University can apply to increase gerontological education access in both urban and rural areas. Such educational opportunities will be a great service to the urban and rural areas of the aging population in the state of Ohio.
\end{abstract}

Keywords: education and training, older adults, continuing education, rural

\section{Introduction}

The U.S. is beginning to experience a rapid increase in the population of older adults that reside in rural areas. Nearly a quarter of the country's population lives in rural designated areas, with those 65 and older representing $17.1 \%$ of the rural population (U.S. Census Bureau, 2013). Although urban areas will see a general increase in their proportion of older adults, the concentration and overall population of older adults residing in rural areas will become much larger due to out-migration of younger age groups and older adults aging in place (Glasgow \& Berry, 2013; Ricketts, 1999). The aging of the population is of general concern to health educators and policy makers due to the increasing need for large numbers of healthcare staff who are appropriately trained to care for the older adult population. Compared to urban healthcare agencies, rural health agencies lack adequately trained staff, have limited resources, and treat a proportionately larger population of older adults (Glasgow \& Brown, 2012). Compared to their urban counterparts, service providers and staff in rural settings have minimal gerontological education and limited access to continuing education opportunities (Glasgow \& Berry, 2013; Glasgow \& Brown, 2012; Goins, Gainor, Pollard, \& Spencer, 2003; Kaempfer, Wellman, \& Himburg, 2002; Ricketts, 1999). The current study provides insight into the differences between urban and rural health care workers' desire and preferences for continuing gerontological education, as well as factors that may restrict workers' abilities to pursue continuing education in rural and urban areas of Ohio. 


\subsection{Social Work Education}

The demand for gerontological social workers has increased, especially in assisted living facilities, social service agencies, hospitals, and home health care agencies (Lun, 2011; Whitaker, Weismiller, \& Clark, 2006). In a national study of licensed social workers, Whitaker and colleagues (2006) found that only three percent of licensed social workers practice in rural areas, compared to 80 percent in metropolitan areas. Nearly three quarters of the licensed social workers surveyed worked with older adults, but only 12 percent of these individuals identified a specialty of "aging." Social workers with an aging specialization were more likely to hold their BSW, have more work experience at the BSW and MSW degree level, and too frequently participate in continuing education opportunities. Unfortunately, the numbers of social work students entering, and those currently in the workforce, lack gerontological training that can be attributed to student specialization selection and minimal gerontological coursework (Cummings \& DeCoster, 2003).

Gelman (2012) interviewed first-year MSW students before and after they were assigned to gerontological field placements. Based on self-reports by students, the exposure of gerontological placements increased the likelihood that these students would work with older adults, as well as increasing their attitudes, knowledge, and appreciation for working with the population. Although field placements and volunteer opportunities with older adults have been shown to have a positive impact on students (Lun, 2011; Authors, 2009), there still exists great variability in the number of graduate programs that offer aging coursework. In an assessment of 144 MSW programs in the country, Cummings and DeCoster (2003) found that only 40 programs offered a specialization, concentration, or certificate in gerontology. The number of MSW programs offering a gerontological focus has continuously declined over the last three decades. The course topics, credit hours, and field placement requirements varied significantly between programs, only further emphasizing the need for aging curricula standards.

\subsection{Nursing Education}

Nurses provide the majority of care to older adults who suffer from a myriad of conditions, such as multiple chronic health conditions, physical disabilities, and mental health issues. Both entry-level nurses and experienced nursing staff have had limited exposure to gerontological competencies which are vital to the treatment and management of older adults with multiple health conditions (Berman et al., 2005; Gilje, Lacey, \& Moore, 2007; Hickman, Newton, Halcomb, Chang, \& Davidson, 2007). With the increasing need for nurses with specialized training, many programs have made significant strides to integrate adequate levels of gerontology/geriatric coursework or training (Berman et al., 2005). In light of the improvements to curricula, many programs still experience barriers to integrating gerontological content, such as the lack of staff credentialed in gerontological nursing, as well as the number of students that are interested in working with older adults (Berman et al., 2005; Burdach \& Rowles, 2012; Deschodt, de Casterlé, \& Milisen, 2009; Gilje et al., 2007).

Continuing education is essential to maintaining and improving the gerontological skills and knowledge base of practicing nurses, as many of these individuals have no formal education in this area (Garton \& Gingold, 2009). In rural areas, nurses typically provide a broad range of services with limited resources and technology that would otherwise be present in more urban health facilities (Jukkala, Henly, \& Lindeke, 2008; McCoy, 2009). Many barriers limit their access to continuing education opportunities, such as travel distance, lack of financial resources, and time (Jukkala et al., 2008; Leson et al., 2014; McCoy, 2009). Continuing education opportunities have been shown to be effective when they engage nurses in the learning process and allow them to apply their acquired knowledge into practice (Barba \& Fay, 2009; Kowlowitz, Davenport, \& Palmer, 2009). New and innovative ways to deliver gerontological continuing education to professionals must be sought with their needs and preferences in mind. Researchers and educators have called for an increased focus on integrating gerontological education into curricula and continuing education for all health care professions (Cummings \& DeCoster, 2003; Goins et al., 2003; Karcher \& Whittlesey, 2007; Authors, 2010) in order to prepare the current and future workforce to treat the complex needs of an aging society. The current study seeks at providing insight on the current needs of professionals working with older adults in urban and rural care settings, as well as factors that may impact their decision to seek continuing education and professional degrees in gerontology.

\section{Methods}

Data were collected in 2011 from for-profit and non-for-profit organizations and professionals working with older adults. A structured survey (paper and electronic) was adapted from Ramirez Corazon and Mayberry's (2005) report on training for rural health and social services professionals and from our instrument asking about specific types of gerontological education. The survey was pilot tested in a three-county area in Northeastern Ohio and modified as necessary. Surveys were sent following the Dillman (2000) survey methodology.

The survey focused on the types of education and the delivery methods that those working with older adults perceive as necessary. A series of items inquiring about types of training desired, most and least preferred methods of educational 
delivery, willingness and distance to travel to obtain education, as well as position type and type of work performed. The data was aggregated and analyzed using SPSS software. Differences in proportion were computed by hand using http://vassarstats.net/propdiff_ind.html.

The final survey was sent to a random sampling of aging related organizations and professionals in 55 of 88 counties in the state of Ohio. Invitations to participate were mailed via the United States Postal Service to 5249 contacts; electronic invitations were sent via Survey Monkey to 1194 contacts for a total of 6443 invitations. Contact information for professionals and organizations was obtained through public record searches, professional organizations, and the database collected by the Department of Gerontology at Youngstown State University, Youngstown, Ohio.

Based upon region of the state, the participants were divided into two groups, urban and rural. Urban areas were based on the number of people who reside within a metro area and are coded with 1,2, and 3 and rural areas of Ohio are classified by the degree of urbanization and adjacency to a metro area and are coded with 4 through 10 (United States Department of Agriculture, 2013). A series of crosstabs were used to analyze the differences between the urban and rural counties of Ohio.

\section{Findings}

\subsection{Sample Description}

The total survey response was 766 participants; 392 electronic and 374 for with an overall response rate of 12 percent. Only professionals and organizations were eliminated if the surveys (both paper and electronic) were returned as undeliverable or as identified as "do not contact". The majority of respondents were female (75.5\%). There was a broad range (20 to 86) with $47.7 \%$ for under age 50 and $61.3 \%$ in the over age 50. Caucasians represented the largest percentage $(92.7 \%)$ of participants by race.

Primary places of employment included for both urban (40\%) and rural (50\%) participants were "Nutrition/Dietetics". The second largest professional group for both urban and rural participants was "Other" with $28 \%$ and $20 \%$, respectively. The professions grouped in the "Other" category included social work, individual and family services, home health, insurance agents, and certified public accountants. Educational attainment among the respondents was high with $91 \%$ of the participants having completed formal degrees that ranged from Associate's level to a PhD, MD, or JD. The majority $(36.4 \%)$ of both urban and rural participants held a terminal Bachelor's degree. Thirty percent of the sample held a Master's degree. Separately, $30.5 \%$ of urban participants and $27.5 \%$ of rural participants received a Master's degree. The differences between highest degree earned and urban-rural variable was found to be significant, but with a small effect size $\left(\chi^{2}(5, \mathrm{~N}=685)=11.90, p=.036, \phi=.132\right)$.

\subsection{Interest in Master's Level Education.}

Participants were asked about their interest in obtaining a master's degree in gerontology. Among the urban participants $17 \%$ were 'very interested' or 'somewhat interested' compared to $24 \%$ of rural participants. Among urban participants 'very interested' or 'somewhat interested' in earning a graduate gerontology certificate was $25 \%$ and $28 \%$ of rural participants. Table 1 identifies the percentage of participants interested in a master's degree and graduate certificate among both urban and rural participants. Rural professional seem to be more interested in obtaining a master's degree or graduate certificate than urban counter parts.

Table 1. Level of interest in gerontology educational programs

\begin{tabular}{lll}
\hline Master's Degree & & \\
Urban Participants & $(\mathrm{n}=507)$ & $17 \%$ \\
Rural Participants & $(\mathrm{n}=93)$ & $24 \%$ \\
Graduate Gerontology Certificate & \\
Urban Participants & $(\mathrm{n}=504)$ & $25 \%$ \\
Rural Participants & $(\mathrm{n}=94)$ & $28 \%$
\end{tabular}

Given the majority of specified preferences were met, $63.7 \%$ of urban participants responded that they were more likely to enroll in a gerontology/geriatric certificate program in the next three years. Similarly, $68.3 \%$ of rural participants would participate.

The maximum time willing to travel one way to attend classes/workshops to earn a gerontology certificate for classes held once a week for both urban and rural drivers was 1 hour $(4, \mathrm{~N}=514)=11.65, p=.020$. Of the 462 urban respondents and 72 rural respondents' most preferred choice training schedule was distance-learning at $39 \%$ and $49 \%$, respectively. 
Table 2. First choice training schedule and willingness to travel to attend classes/workshops to earn gerontology certificate for classes held once a week

\begin{tabular}{|c|c|c|c|}
\hline & Urban & Rural & Total (frequency) \\
\hline \multicolumn{4}{|c|}{ First Choice Training Schedule $(n=527)$} \\
\hline Half-Day Weekend & 64 & 4 & 68 \\
\hline Full-Day Weekend & 34 & 9 & 43 \\
\hline 2-3 Hours Weekday Evening ${ }^{a}$ & 85 & 8 & 93 \\
\hline All Day Saturday & 65 & 10 & 75 \\
\hline All day Saturday/ Half-Day Sunday & 28 & 6 & 34 \\
\hline Distance Learning & 179 & 35 & 214 \\
\hline Other Times & 7 & 0 & 7 \\
\hline \multicolumn{4}{|l|}{ Willingness to travel $*(n=514)$} \\
\hline 1.0 hour $^{1}$ & 347 & 47 & 394 \\
\hline 1.5 hours $^{2}$ & 49 & 16 & 65 \\
\hline 2.0 hours $^{3}$ & 29 & 9 & 38 \\
\hline 2.5 hours & 8 & 0 & 8 \\
\hline $3.0+$ hours & 8 & 1 & 9 \\
\hline
\end{tabular}

Note. *Results were significant at the $\mathrm{p}<.05$ level.

${ }^{\mathrm{a}} \mathrm{z}$-score $=-1.52, \mathrm{p}=.06$

${ }^{1} \mathrm{Z}$-score $=-2.68, \mathrm{p} \leq .01$

${ }^{2} \mathrm{z}$-score $=2.57, \mathrm{p}<.01$

${ }^{3} \mathrm{z}$-score $=1.74, \mathrm{p}>.05$.

Top three factors preventing participants from receiving further training were the same for both urban and rural participants. Fifty-four percent of urban participants and $62 \%$ of rural participants perceive 'limited time' as a factor that would prevent them from seeking further training. 'Scheduling issues' were a problem for $20 \%$ of urban participants and $14 \%$ of rural participants. 'High costs' was the third issue for $14 \%$ of urban participants and $6 \%$ of rural participants. Tests for difference in proportion show that a greater proportion of rural participants were willing to take 2-3 hours of evening classes during the work week (see Table 2).

The preferred maximum travel time each way to attend classes/workshops held once a week for a gerontology certificate was one hour for both urban and rural participants; Table 2. A greater proportion of rural participants would consider driving an hour and a half to two hours for educational opportunities. This is helpful information when coupled with the results of both urban and rural participants preference of distance-learning. These two preferences by participants can help make a gerontology education program versatile by offering distance-learning centers that can be within a one hour commute rather than just having a central location for all of the program's facilities. This could help increase interest enrollment into a gerontology program, which was reported 'very likely' or 'somewhat likely' at $63.7 \%$ and $68.3 \%$ for urban and rural participants, respectively, in the next three years.

The high level of education of the respondents could help with future implications for increasing gerontological education in urban and rural areas of Ohio. When urban and rural residents in Ohio were compared to each other by in terms of education, significant differences were found $(5, \mathrm{~N}=685)=11.90, p=.036$. The results showed that bachelor's and master's degrees stand out as they have greater percentages; Table 3.

Table 3. Highest Degree Earned By Urban and Rural Participants $(n=685)$

\begin{tabular}{ll}
\hline Some High School & \\
Urban Participants & $1.9 \%$ \\
Rural Participants & $.01 \%$ \\
Total Participants & $1.8 \%$ \\
Associate's Degree & \\
Urban Participants & $5.7 \%$ \\
Rural Participants & $13.7 \%$ \\
Total Participants & $6.9 \%$ \\
Bachelor's Degree & \\
Urban Participants & $36.5 \%$ \\
Rural Participants & $35.3 \%$ \\
Total Participants & $36.4 \%$ \\
Master's Degree & \\
Urban Participants & $30.5 \%$ \\
Rural Participants & $27.5 \%$ \\
Total Participants & $30.1 \%$ \\
PhD, MD, or JD & \\
Urban Participants & $16.8 \%$ \\
Rural Participants & $10.8 \%$ \\
Total Participants & $15.9 \%$ \\
Other & \\
Urban Participants & $8.6 \%$ \\
Rural Participants & $11.8 \%$ \\
Total Participants & $9.1 \%$ \\
\hline
\end{tabular}

Note. Results were significant at the $\mathrm{p}<.05$ level. 
The top three factors that would prevent participants from receiving further training in gerontological education are presented in Table 4. 'Limited Time' was the perceived as the most important factor to prevention of further training. This could explain why most participants prefer an hour commute for their maximum distance willing to travel and their preference for distance-learning. Short commutes and distance-learning could help compensate for the perception of limited time to earn an advanced degree in gerontology. 'Scheduling Issues' and 'High Cost' were the next two factors that could prevent further training.

Table 4. Top Factors Preventing Participants From Further Training ( $\mathrm{n}=349)$

\begin{tabular}{llll}
\hline & Urban & Rural & Total (percent) \\
\hline Top Factors Preventing Further Training & & & \\
Limited Time & $53.8 \%$ & $62 \%$ & $55 \%$ \\
Scheduling Issues & $20 \%$ & $14 \%$ & $19.2 \%$ \\
Cost Too High & $14 \%$ & $6 \%$ & $12.9 \%$ \\
No Factor & $4 \%$ & $6 \%$ & $4.3 \%$ \\
Not Interested in Topic & $4.3 \%$ & $4 \%$ & $4.3 \%$ \\
Too Far Away & $1.7 \%$ & $6 \%$ & $2.3 \%$ \\
Other & $2 \%$ & $2 \%$ & $2 \%$ \\
\hline
\end{tabular}

\section{Discussion}

Results from this study are promising and shows that the field of gerontology has room for growth in the state of Ohio. Urban and rural areas were found to have similar interests in gerontological education but with difference levels of interest. Based on this and on previous research stating different services used and required in urban and rural areas different strategies can be utilized to bolster gerontological education in those areas. A reason for this is that professionals in rural areas of Ohio may believe there is a greater need for those gerontological education programs so that staff can better assist the residents in rural areas. Providing a master's degree or a graduate certificate could be a possibility for increasing gerontological education in both urban and rural areas that already have a bachelor's degree or a master's degree, respectfully. Gerontology programs that are flexible and versatile in offering educational degrees or certificates could help encourage urban and rural residents to enroll and pursue further education.

The current study examined the differences and similarities in urban and rural gerontological needs in the state of Ohio. Despite every attempt to obtain a representative sample of professionals in aging, limitations are still present. Limitations include a smaller than expected response rate. This is in part due to the poor quality of the mailing list obtained from an external vendor that had many bad addresses or agencies that were outside of our sampling frame. The next limitation is focusing only on Ohio limits the generalizability of the sample, though Ohio has a long track record of gerontological education from the member institutions of the Ohio Association of Gerontology and Education and a strong aging network. The high level of education could represent a response bias. Perhaps those who did not respond were not highly educated or didn't understand the value of completing survey research. There may have been underlying mechanisms that prevented them from responding, such as education level, and this might not have been a problem for those who did respond.

The current research indicates that there is an interest to pursue further education in both urban and rural residents in the state of Ohio. There is better understanding for methods to implement a gerontological education and formal training programs that would be more effective in urban areas of the state and rural areas. Rural areas in Ohio report greater interest because the aging populations in these areas are increasing at a faster rate than metro areas. Future research will have to address this rapid growth in rural areas and increasing knowledge of gerontology education in those areas would help better serve the aging population.

\section{Acknowledgements:}

The authors would like to thank Dr. Qi Jiang, chair of the Department of Sociology, Anthropology, and Gerontology at Youngstown State University for her support on this project. We would also like to thank Cassandra Valentini for her help in the mailing and data entry processes on this project.

Financial Support for this manuscript comes from a Youngstown State University URC grant which helped with mailing and data entry costs.

\section{References}

Barba, B. D, \& Fay, V. (2009). Does continuing education in gerontology lead to changes in nursing practice? Journal of Gerontological Nursing, 35(4), 11-17.

Bardach, S. H., \& Rowles, G. D. (2012). Geriatric education in the health professions: Are we making progress? The Gerontologist, 52(5), 607-618. http://dx.doi.org/10.1093/geront/gns006

Berman, A., Mezey, M., Kobayashi, M., Fulmer, T., Stanley, J., Thornlow, D., \& Rosenfeld, P. (2005). Gerontological 
nursing content in baccalaureate nursing programs: Comparison of findings from 1997 and 2003. Journal of Professional Nursing, 21(5), 268-275. http://dx.doi.org/10.1016/j.profnurs.2005.07.005

Cummings, S. M., \& DeCoster, V. A. (2003). The status of specialized gerontological training in graduate social work education. Educational Gerontology, 29(3), 235-250. http://dx.doi.org/10.1080/713844304

Deschodt, M., de Casterl, B., \& Milisen, K. (2010). Gerontological care in nursing education programmes. Journal of Advanced Nursing, 66(1), 139-148.

Dillman, D. (2000). Mail and Internet Surveys: The Tailored Design Method. New York: John Wiley.

Garton, R., \& Gingold, W. (2009). Priorities for continuing education in geriatrics: perceptions among various groups. Journal of Gerontological Nursing, 35(4), 18-25. Retrieved on March 3, 2014 from Academic Search Complete.

Gelman, C. (2012). Transformative learning: First-year MSW students' reactions to, and experiences in, gerontological field placements. Educational Gerontology, 38(1), 56-69. http://dx.doi.org/10.1080/03601277.2010.500579

Gilje, F., Lacey, L., \& Moore, C. (2007). Gerontology and geriatric issues and trends in U.S. nursing programs: A national survey. Journal of Professional Nursing, 23(1), 21-29. http://dx.doi.org/10.1016/j.profnurs.2006.12.001

Glasgow, N., \& Berry, E. H. (2013). Rural Aging in $21^{s t}$ Century America. New York, NY: Springer Publishing Co. http://dx.doi.org/10.1007/978-94-007-5567-3

Glasgow, N., \& Brown, D. L. (2012). Rural ageing in the United States: Trends and contexts. Journal of Rural Studies, 28(4), 422-431. http://dx.doi.org/10.1016/j.jrurstud.2012.01.002

Goins, R. T., Gainor, S. J., Pollard, C., \& Spencer, S. M. (2003). Geriatric knowledge and educational needs among rural health care professionals. Educational Gerontology, 29(3), 261-272. http://dx.doi.org/10.1080/713844301

Hickman, L., Newton, P., Halcomb, E. J., Chang, E., \& Davidson, P. (2007). Best practice interventions to improve the management of older people in acute care settings: a literature review. Journal of Advanced Nursing, 60(2), 113-126. http://dx.doi.org/10.1111/j.1365-2648.2007.04417.x

Jukkala, A. M., Henly, S. J., \& Lindeke, L. L. (2008). Rural perceptions of continuing professional education. The Journal of Continuing Education in Nursing, 39(12), 555-563. Retrieved on August 22, 2014 from University Database. http://dx.doi.org/10.3928/00220124-20081201-08

Kaempfer, D., Wellman, N., \& Himburg, S. (2002). Dietetics students' low knowledge, attitude, and work preferences toward older adults indicate need for improved education about aging. Journal of the American Dietetic Association, 102(2), 197-202. http://dx.doi.org/10.1016/S0002-8223(02)90048-9

Karcher, B. C., \& Whittlesey, V. (2007). Bridging the gap between academic gerontology and the educational needs of the aging network. Educational Gerontology, 33(3), 209-220. http://dx.doi.org/10.1080/03601270600894055

Kowlowitz, V., Davenport, C., \& Palmer, M. (2009). Development and dissemination of Web-based clinical simulations for continuing geriatric nursing education. Journal of Gerontological Nursing, 35(4), 37-43. Retrieved on March 3, 2014 from Academic Search Complete.

Lowry, R. (2014). The Significance of the Difference Between Two Independent Proportions. http://vassarstats.net/propdiff_ind.html?

Lun, M. W. (2012). Student knowledge of aging and career preferences. Educational Gerontology, 38, 70-79. http://dx.doi.org/10.1080/03601277.2010.500584

McCoy, C. (2009). Professional development in rural nursing: Challenges and opportunities. The Journal of Continuing Education in Nursing, 40(3), 128-131. http://dx.doi.org/10.3928/00220124-20090301-08

Ramírez Corazón, J., \& Mayberry, P. (2005). Gerontology \& geriatrics training for rural health \& social services professionals in western and central New York. Internal Report

Ricketts, T. C. (1999). Rural Health in the United States. New York, NY: Oxford University Press.

U.S. Census Bureau. (2013). American Community Survey. http://factfinder2.census.gov/faces/nav/jsf/pages/searchresults.xhtml?refresh=t

Whitaker, T., Weismiller, T., \& Clark, E. (2006). Assuring the sufficiency of a frontline workforce: A National Study of Licensed Social Workers. Special Report: Social Work Services for Older Adults. Washington, DC: National Association of Social Workers.

\section{(cc) BY}

This work is licensed under a Creative Commons Attribution 3.0 License. 